\title{
Algumas lições da reforma administrativa italiana nos anos 1990
}

\author{
Davide Carbonai \\ Universidade Federal do Rio Grande do Sul (UFRGS) \\ Alfredo Alejandro Gugliano \\ Universidade Federal do Rio Grande do Sul (UFRGS)
}

O artigo analisa a relação entre crise política e reforma da administração pública italiana na década de noventa. Os autores apresentam as principais características dessa reforma e, a partir de um banco de dados baseado em informações coletadas em 209 administrações locais italianas, discutem os resultados da implementação dessas políticas em termos de mudanças da administração pública.

Palavras-chave: administração pública, reforma administrativa, crise econômica

\section{Algunas lecciones de la reforma administrativa italiana en los años 1990}

El artículo analiza la relación entre crisis política y reforma de la administración pública italiana en la década de los noventa. Los autores presentan las principales características de esta reforma y, a partir de un banco de datos basado en informaciones recolectadas en 209 administraciones locales italianas, discuten los resultados de la implementación de esas políticas en términos de los cambios en la administración pública.

Palabras clave: administración pública, reforma administrativa, crisis económica

\section{Some lessons from the italian administrative reform in the $1990 \mathrm{~s}$}

The paper analyses the relationship between political crisis and Italian administrative reform in the decade of the 1990s'. The authors introduce the main characteristics of this reform and, based on a dataset and information collected from 209 Italian local administrations, they discusses the consequences of this reform in terms of changes in public administration.

Keywords: public administration, administrative reform, economic crisis

[Artigo submetido em 11 de setembro de 2015. Aprovado em 9 de fevereiro de 2017.] 


\title{
Introdução
}

Quando no Brasil se discutem os problemas derivados da corrupção, em boa medida envolvendo políticos profissionais, funcionários públicos e setor privado, um dos exemplos que surge no horizonte é o caso italiano, a experiência no combate ao envolvimento de políticos com atividades ilegais por meio da operação mani pulite (mãos limpas): uma megaoperação judicial, realizada a partir de 1992, com o intuito de frear a corrupção no aparato estatal.

Menos divulgado é que, junto ao combate à corrupção via processos judiciais, a Itália iniciou naquele período um processo de reforma administrativa do Estado, visando diferenciar, principalmente, funções políticas de funções técnicas do ente público.

O modelo gerencial de reforma administrativa do Estado italiano esteve baseado em quatro princípios: a) ampliação da capacidade de gestão do gerente público; b) redução da interferência administrativa dos cargos comissionados, frequentemente indicados pelos partidos políticos; c) premiação dos funcionários públicos por desempenho; d) descentralização do sistema de relações trabalhistas do funcionalismo público.

Entre o final dos anos 1980 e o início dos anos 1990 a Itália enfrentou uma série de conturbações geradas pela crise da maioria dos partidos políticos que nasceram ou se consolidaram na Primeira República (1945-1994), especialmente a Democracia-Cristã, tensão aprofundada pelo desvelamento de uma grande teia de corrupção que marcou o fim de uma época. Na opinião de Norberto Bobbio, nesse processo:

\begin{abstract}
A Primeira República morreu [...] por consunção [...]. Desgastada internamente pela corrupção, pelo mau governo, pelo não-governo: dominada pelo excessivo poder dos partidos, especialmente dos partidos de governo, que gozaram de uma espécie de imunidade pela situação de privilégio na qual se encontravam [...] (BовBIO, 2001, p. 134).
\end{abstract}

Mesmo num contexto diverso ao italiano, nos últimos anos as reformas administrativas na esfera estatal também foram matéria recorrente em praticamente todos os países latino-americanos (ECHEBARRIA; CORTAZAR, 2007) 1 . Em boa medida, houve um esforço por reduzir o tamanho do Estado, oferecendo condições para a ampliação do processo de privatização de áreas antes controladas

\footnotetext{
${ }^{1}$ Essa foi uma agenda de discussão inserida com maior contundência a partir dos anos noventa do século 20, um período, segundo David Harvey (2007), marcado pela dissolução do bloco de países comunistas e fim da Guerra Fria, expansão da globalização e do neoliberalismo enquanto modelo administrativo gerencial.
} 
pela via estatal, como seria o caso do setor energético e outros segmentos considerados economicamente estratégicos, assim como redução do número de funcionários públicos.

No Brasil, tais reformas igualmente fizeram parte da pauta de discussões no período pós-redemocratização, sendo, inclusive, criado um órgão específico para sua implementação, o Ministério da Administração Federal e Reforma do Estado (Mare), funcionando entre 1995-1998 (LIMA JR., 1998; PEREIRA, 1998). Ademais, no País diversos governos estaduais apontaram a reforma da administração pública como um caminho inevitável para combater a crise econômica, estratégia com fortes implicações nas políticas públicas regionais e seus efeitos (ABRUCIO, 2007; Longo, 2007; PEREIRA; SPINK, 2007; SOUSA; CARVAlHo, 1999).

Na presente conjuntura, a organização de uma agenda de reformas na estrutura estatal ganha ainda maior relevância. Assim sendo, este texto se ocupa da trajetória da reforma administrativa italiana e seus principais resultados: experiência que oferece diversos exemplos que podem auxiliar o debate brasileiro sobre a questão. Nele, abordamos a reforma italiana a partir do contexto europeu e da formação da União Europeia (UE).

O artigo é desenvolvido por meio da apresentação e análise das principais medidas dessa reforma e sua concretização, notadamente, as consequências das mudanças introduzidas no sistema de relações de trabalho. Em especial, são proporcionados dados de uma pesquisa realizada, em 2008, junto aos entes locais italianos (municípios e províncias).

Os governos municipais ofereceram informações relevantes sobre a efetividade das mudanças propostas na gestão pública local. Nas conclusões, reforçamos a ideia de que as reformas pretendidas não chegaram a um bom termo, entre outros motivos, por causa da inadequação de estratégias tipicamente empresariais em contextos diferentes do setor privado.

\section{A administração pública italiana diante da incorporação na União Europeia}

Na Itália, a década de integração ao projeto europeu foi marcada pelo desequilíbrio das contas públicas, fraco crescimento econômico e - como uma das consequências disso - uma política de reformas, mirando modificar a estrutura política, econômica e social do país, visando adequá-las aos padrões da União Europeia².

${ }^{2}$ A Itália participa da União Europeia desde sua fundação pós-Tratado de Maastrich, em 1992. 
No campo parlamentar, foram realizadas microrreformas na Câmara e no Senado, aspirando fortalecer o papel do governo no processo decisório, racionalizar a relação entre os partidos políticos e a administração pública, assim como implantar uma nova política trabalhista (RICCI, 2006; BARBIERI; SCHERER, 2005) 3 .

Ademais, ocorreu um processo de renovação dos instrumentos de gestão e controle da administração pública italiana, desencadeado pela edição de nova regulamentação dirigida a estimular a transparência administrativa, racionalizar a administração pública, regulamentar o direito à greve em serviços essenciais, entre outros $^{4}$. Foi criada igualmente uma legislação inédita com o fim de estabelecer parâmetros de despesas financeiras mais rígidos, o Patto di stabilità interno introduzido na legislação a partir de 1999 - que passou a ser aplicado também às administrações regionais e municipais ${ }^{5}$.

Concomitantemente houve uma profunda mudança nas relações entre sindicatos e governo. Como veremos mais detalhadamente adiante, se por um lado as relações entre as organizações sindicais e os gestores públicos se tornaram mais democráticas e inclusivas, por outro lado houve uma forte redução de recursos disponíveis para despesas públicas (BACCARO, 2008) ${ }^{6}$.

Em boa medida, essas políticas visaram atacar um dos problemas crônicos do Estado italiano: a dívida pública que chegou a cerca de $130 \%$ do PIB em 2013. De acordo com Sismondi (2013), uma fonte considerável dessa despesa é gerada pelos custos do funcionalismo público: na primeira década do século 21, a incidência global da despesa com o funcionalismo em relação ao PIB chegou a $10,8 \%$. No mesmo período, o endividamento per capita em municípios como Turim chegou a 3.800 euros per capita em função dos custos com o funcionalismo.

$\mathrm{Na}$ Itália, ao longo do tempo, cresceram também as críticas aos altos custos do sistema político parlamentar e das políticas públicas em nível nacional e também local. A questão do "desperdício de dinheiro público" tornou-se popular na mídia e

\footnotetext{
${ }_{3}^{3}$ Por exemplo, o Pacchetto Treu, a Lei no 196, de 24 de junho de 1997, que introduz formas de contratação flexíveis, como o contrato por prazo determinado.

${ }^{4}$ São exemplos disso: a) Lei no 241, de 1990, sobre a transparência administrativa; b) a Lei no 421, de 1992, que trata das normas de racionalização da administração pública; c) Lei no 146, de 1990; e d) Lei no 83, de 2000, ambas relacionadas com a regulamentação das greves em serviços públicos essenciais.

${ }^{5}$ Um quadro geral das leis que fundamentaram as últimas reformas da administração pública italiana pode ser encontrado em: Ongaro (2009), Amato et al. (2009, p. 158-171) e Gentile (2012).

${ }^{6}$ De fato, a crise da dívida interna levou a uma drástica redução de investimentos, principalmente daquela parte do orçamento nacional destinada às políticas de saúde, educação e transferências de recursos para os entes locais.
} 
ainda mais no debate político, evidenciando críticas especialmente ao tamanho da máquina pública e seu número de funcionários ${ }^{7}$.

O funcionalismo público italiano representava em 2010, em termos do total de trabalhadores empregados no setor, aproximadamente $5,6 \%$ da população italiana: cerca de 3,4 milhões de servidores. Todavia, essa porcentagem também variava entre as regiões.

Enquanto na Calábria, localizada no sul da Itália, $13 \%$ do número total de trabalhadores formais no mercado de trabalho eram funcionários públicos, na região da Lombardia, ao norte do país, esse número nunca passou de $6 \%$ do total de trabalhadores. Soma-se a isso o fato de que a mobilidade dos funcionários públicos é praticamente inexistente. Em 2011, apenas um empregado em cada mil mudou de ente administrativo, enquanto um a cada cem trocou de setor administrativo, mas permaneceu no mesmo local de trabalho, sendo todas solicitações de transferência voluntárias, sem qualquer interferência direta do gestor público (SISMONDI, 2013) . $^{8}$

É importante ainda salientar outras características dos servidores públicos italianos. Em termos etários, enquanto na França a porcentagem de funcionários públicos com menos de 35 anos de idade era, na primeira década do século 21 , de $28 \%$ do total de funcionários estatais e, no Reino Unido, aproximadamente $25 \%$ desse mesmo universo de trabalhadores, na Itália essa porcentagem era de menos de $10 \%$. Em alguns setores, esse envelhecimento do funcionalismo público é evidente: a porcentagem de trabalhadores com menos de 25 anos de idade diretamente empregados nas universidades, por exemplo, é praticamente zero.

Além disso, a administração pública italiana, em comparação com França e Inglaterra, tem a menor porcentagem de mulheres concursadas no setor: $55 \%$ dos funcionários públicos na Itália, contra $61 \%$ na França e $65 \%$ no Reino Unido. Entre os países membros da União Européia, a Itália possui um dos piores indicadores de inclusão das mulheres em cargos de chefia no setor público: uma mulher a cada nove homens (SISMONDI, 2013).

O crescimento salarial no serviço público, no final da década de 1980, juntamente à necessidade de convergência perante os parâmetros econômicos e financeiros definidos pela UE, levou à aceleração da implantação de medidas visando reestruturar o aparelho administrativo. Entre as mesmas, podemos

\footnotetext{
7 Um exemplo da grande repercussão desse tema na opinião pública foi a vendagem do livro La Casta (RIzzo; STELLA, 2007). Publicada por dois jornalistas investigativos com a intenção de denunciar a corrupção governamental e o mau uso de verbas públicas por parlamentares, a obra chegou a vender mais de um milhão de exemplares poucos meses após seu lançamento.

${ }^{8}$ A questão está presente no Decreto Lei n. 90 de Junho de 2014, emitido pelo Governo de Matteo Renzi: além de facilitar a mobilidade voluntária entre entes, o Decreto introduz a mobilidade obrigatória num raio 50 quilômetros.
} 
destacar a redução de gastos públicos, a implementação de novas estratégias de inovação organizacional e, notadamente, um incentivo à maior produtividade e aproveitamento dos recursos humanos ${ }^{9}$.

Essa reorientação atingiu a gestão pública de forma geral, porém, os entes locais foram alvo dessas medidas de maneira mais significativa e abrangente, particularmente as comunas e as províncias nas quais trabalham, em média, 17\% dos servidores públicos italianos, cerca de 516 mil servidores (SISMONDI, 2013) ${ }^{10}$.

A lógica que inspirou a reforma da administração pública italiana foi a da importação para entes públicos de alguns modelos consagrados na gestão das organizações econômicas privadas. Isso estimulou a criação de modelos organizacionais com estruturas mais enxutas e ágeis, voltadas para a obtenção de resultados conforme critérios de eficiência e eficácia.

A execução desses objetivos foi possibilitada também pela aprovação de um conjunto de leis que permitiram rever a organização das relações de trabalho no setor público e estimularam a realização de negociações laborais em nível dos entes locais (acordos de segundo nível) subordinadas aos acordos coletivos de trabalho em nível nacional (acordos de primeiro nível) ${ }^{11}$.

Esse processo de reforma da administração italiana visou responder a dois problemas próprios dos sistemas burocráticos, também destacados na literatura sobre Nova Gestão Pública (PolLITT; BOUCKAERT, 2002): 1) a ineficiência da administração por causa do excesso de procedimentos e controles processuais; 2) a baixa responsabilização dos burocratas em face do sistema político e da sociedade, que, no caso italiano, é resolvida de várias formas, entre as quais, e sobretudo, a reorganização do sistema contratual.

\footnotetext{
${ }^{9}$ Os servidores italianos têm salários equivalentes aos colegas europeus, mas, em média, mais elevados do que no setor privado. Em comparação com França e Inglaterra, os salários médios são semelhantes nos três países, mas enquanto no Reino Unido são ligeiramente mais baixos do que o setor privado e na França estão alinhados, na Itália os funcionários públicos ganham em média $49 \%$ a mais do que os trabalhadores privados. Aliás, a dinâmica dos salários dos servidores públicos sofreu um salto de $7 \%$ ao ano no período entre 2000 e 2005, com uma diferença de mais de quatro pontos percentuais em comparação com o setor privado. A partir de 2006, a evolução salarial dos funcionários públicos e trabalhadores no setor privado tende a alinhar-se (SISMONDI, 2013, p. 7).

${ }^{10}$ Ricciardi (2012) oferece uma leitura crítica das transformações ocorridas na administração pública italiana nos últimos vinte anos. Resumidamente, pelo que se refere à administração local, a comuna (comune) representa a unidade básica de organização administrativa na Itália (equivalente ao município no Brasil). Sua estrutura é constituída pelo sindaco, equivalente ao prefeito no Brasil, pelo conselho comunal (consiglio comunale) composto por um número variável de conselheiros eleitos - e pela junta municipal (um grupo de assessores, escolhidos pelo sindaco). Ainda que cada comuna pertença a uma província (provincia) - 8015 comunas incluídas em 107 províncias - a comuna é um ente local autônomo e independente.

${ }^{11}$ Notadamente o Decreto Legislativo no 80 e o Decreto Legislativo no 387 de 1998.
} 
Afinal, em linha com os princípios dessa perspectiva, a proposta italiana em questão combinou a flexibilização da gestão (in primis, por meio da reforma contratual do funcionalismo público) com um maior empoderamento por parte da administração pública, utilizando uma accountability na qual os servidores receberiam prêmios de acordo com uma avaliação realizada pelos chefes de seção que, por sua vez, também seriam avaliados pelo sistema político-partidário.

A introdução no quadro administrativo de trabalhadores não concursados, mas contratados a tempo parcial (contratos temporários); a redução de transferências de recursos por parte do governo central, assim como a privatização de serviços, para citar alguns exemplos, configuram o caso italiano como uma tentativa de reforma estatal, conforme os princípios da Nova Gestão Pública. Segundo Sano e Abrucio (2008), a nova gestão pública se caracteriza por:

a) A adoção de uma administração pública voltada para resultados, baseada em mecanismos de contratualidade da gestão, com metas, indicadores e formas de cobrar os gestores, e apoiada na transparência das ações governamentais, possibilitando o controle maior dos cidadãos e o uso de outros instrumentos de accountability. b) A contratualidade supõe, ademais, a existência de uma pluralidade de provedores de serviços públicos - (...). Desse modo, é possível estabelecer formas contratuais de gestão em estruturas estatais e entes públicos não estatais. c) Por fim, a combinação entre a flexibilização da gestão burocrática e o aumento da responsabilização da administração pública será mais bem-sucedida caso funcionem adequadamente os mecanismos institucionais de controle (...). Como veremos adiante, esse é o aspecto mais intrincado no caso brasileiro (SANO; ABRUCIO, 2008, p. 66).

\section{Características da reforma administrativa dos anos 1990}

Morón (1994) considera que, a partir dos anos 1970, o Estado italiano foi vítima de dois problemas crônicos. Por um lado, a ineficácia administrativa gerada por uma corrupção generalizada envolvendo um forte esquema de pagamento de propinas que ligava administradores públicos a grupos de interesses legais e ilegais, alimentando um alto déficit público e inflação. Por outro lado, um sistema de partidos políticos que submetia o aparato administrativo público aos interesses partidários.

Diante dessa situação, nos anos noventa do século passado foi iniciada uma reforma administrativa cujo principal pano de fundo foi a tentativa de reduzir a interferência dos partidos políticos na administração pública, valorizando o caráter técnico da atividade de gestão. 
Para isso, o alvo central da reforma administrativa italiana foi a modernização da função pública partindo da base do sistema, isto é, o funcionalismo especialmente em nível local. Por exemplo, no sistema contratual anterior à reforma, o tema da progressão funcional do servidor estava diretamente vinculado ao tempo de serviço. No novo sistema contratual, houve a tentativa de recompensar os funcionários segundo critérios de mérito, como o seu desempenho, competências, flexibilidade funcional e versatilidade no desenvolvimento de diversas atividades. A quota de salário a ser acrescida seria flexível, estabelecida pela administração local conforme os critérios de repartição do fundo de produtividade estabelecidos pelo ente e suas disponibilidades econômicas e financeiras.

Em 1993 foi criada a Agenzia per la Rappresentanza Negoziale nelle Pubbliche Amministrazioni (ARAN), cujo objetivo foi representar o ente público nas relações trabalhistas com os sindicatos dos servidores, negociando e assinando contratos coletivos de trabalho diretamente com os mesmos. A partir daí, toda contratação nacional começou a ser definida por meio das relações trabalhistas entre a ARAN e os sindicatos dos servidores públicos organizados em nível nacional.

O contrato nacional determinaria o piso salarial e as normas gerais da organização do trabalho; já os conteúdos específicos das contratações seriam definidos em nível dos entes locais e envolveriam negociação entre representantes governamentais o prefeito, no caso das comunas - e os funcionários organizados no sindicato local (BORDOGNA, 1998).

Esse esquema contratual diferenciado favoreceu uma nova abordagem relativa à remuneração do trabalho do servidor, baseada no critério de performance related pay: uma maneira de tentar vincular parte dos salários à produtividade e ao desempenho organizacional de cada funcionário, assim como ao cumprimento de metas preestabelecidas, conforme critérios gerais de eficiência e eficácia organizacional.

Foi instituíd o um novo procedimento de contratação centrado em enquadramento funcional de tipo broad banding (faixas largas) permitindo, além da mobilidade vertical entre quatro faixas (enquadramento $A, B, C$ e $D$ ), também a progressão horizontal em quatro subfaixas ( $A 1, A 2, A 3, A 4 ; B 1, B 2$, etc.), aproximando-se de um modelo anteriormente utilizado no setor químico italiano.

A mobilidade vertical somente seria possível por concurso, enquanto que a mobilidade horizontal dentro das quatro faixas poderia ser aprovada pelos dirigentes administrativos conforme critérios meritocráticos definidos pela contratação descentralizada.

Partindo de uma negociação nacional, a reforma buscou vincular a renovação das práticas administrativas à contratação descentralizada em nível local. Isto é, 
apesar das regras gerais terem sido definidas a partir de um contrato nacional de referência, seriam os entes locais e os sindicatos de servidores públicos os responsáveis pelas normas de trabalhos e os conteúdos da contratação.

Enquanto o contrato nacional fixaria o salário básico, as normas e regras de avaliação de resultados gerais, o contrato local articularia os conteúdos do contrato coletivo nacional conforme um conjunto de normas decididas ad hoc por cada administração, definindo com exatidão os critérios de repartição da quota orçamentária de salário variável, os prêmios de produção, as progressões verticais e horizontais, assim como as tarefas e rotinas de trabalho.

Outro dos eixos fundamentais implantados pela reforma foi a alteração do modelo administrativo vigente nas administrações locais. Pela nova proposta, seria criada a figura dos gerentes departamentais que seriam os principais avaliadores do desempenho dos servidores, de acordo com critérios orientados a efetivar os objetivos definidos pela administração.

Desse modo, a reforma pretendeu reforçar as diferenças funcionais entre gerentes e dirigentes políticos: os primeiros sendo incumbidos das decisões técnicas e implementação das metas governamentais; os segundos, responsáveis por fundamentar e fixar as metas gerais da administração que deveriam ser executadas pelo corpo técnico (CRISTOFOLI et al., 2007).

\section{Apontamentos sobre os resultados da reforma administrativa}

O balanço dos resultados da reforma administrativa é crítico. Inicialmente, porque a contratação descentralizada acabou não favorecendo a distribuição dos prêmios baseados em resultados ou critérios de mérito. Ao contrário disso, os avaliadores e avaliados passaram a pactuar o fundo municipal destinado ao salário de produtividade sem utilizar critérios relacionados com o desempenho do servidor (BORdognA, 2003; CARRIERI; RICCIARDI, 2006).

Nessa negociação os servidores públicos, organizados nos sindicatos, se comprometiam a evitar piquetes, protestos ou greves que paralisassem a função pública; em contrapartida, os administradores locais evitariam aplicar a reforma in toto, tornando sem efeito a diferenciação dos servidores conforme critérios de desempenho (CARBonal; SORDINI, 2006). Consequentemente, o tempo de serviço se manteve como principal propulsor da progressão funcional, semelhantemente ao período anterior.

O sistema de avaliação introduzido pela reforma pretendeu estimular a competição entre os trabalhadores vinculados à máquina pública, seccionando o setor entre aqueles que seriam mais bem remunerados em função da sua eficiência 
e os outros servidores sem condições de aceder a esse benefício. Todavia, na prática o modelo foi ineficiente considerando que, na maioria dos entes locais, todos os servidores públicos foram avaliados de forma a atingir as metas delineadas pela administração; por consequência, receberam parcelas equivalentes da quota de salário que deveria ser variável (D’ALOIA, 2006).

Em vez de criar uma diferenciação salarial seguindo critérios meritocráticos, a reforma acabou gerando uma forma indireta de abono salarial universal, estabelecendo novos mecanismos informais de negociação salarial entre chefias e trabalhadores e, consequentemente, robustecendo ainda mais o espírito corporativista no interior da administração pública.

A inoperância das gerências em termos da avaliação de resultado das atividades dos servidores, em boa medida, foi fruto da incapacidade dos governos locais de estabelecerem um planejamento prévio de diretrizes e metas a serem cumpridas a curto, médio e longo prazo (DELLA RocCA, 2009).

Sendo frequente o atraso da aprovação do orçamento público nos entes públicos italianos, foi praticamente impossível o balanço das atividades dos servidores de acordo com um planejamento de metas previamente fixadas, fato que levou boa parte dos gerentes públicos a optarem por redistribuir a quota orçamentária de produtividade de forma igualitária, comprometendo os fundamentos produtivistas da reforma (CARBONAI; SORDINI, 2006).

Como mencionado, a reforma teve entre suas metas capitais a proposta de reforçar a diferença de funções entre os agentes políticos (prefeitos, vereadores, secretários, cargos comissionados etc.) e os funcionários públicos de carreira. No corpo desse projeto, claramente os políticos profissionais estabeleceriam as prioridades e metas da administração, já os funcionários apenas executariam funções previstas no contrato sob a supervisão e avaliação de gerentes guiados por critérios de desempenho estritos.

Porém, no momento de colocar a proposta em prática, a propalada diferenciação não foi efetivada, considerando que os funcionários com nomeação política continuaram monopolizando postos de comando na administração e interferindo decisivamente em questões cujos critérios deveriam ser técnicos.

Igualmente a reforma falhou em termos da redução do impacto da terceirização do trabalho no setor público, o que comprometeu a meta de constituição de um corpo técnico qualificado e eficiente nos marcos da administração pública, considerando que em quase $80 \%$ das administrações locais ainda era utilizado um número considerável de trabalhadores contratados por prazo determinado no final da primeira década do século 21 (AмATo et al., 2009). 
De um modo geral, a reforma administrativa fundamentou-se na ideia de que, em termos de relações trabalhistas na administração pública local, as boas práticas favoreceriam a introdução e o uso de uma melhor dinâmica organizativa. Assim sendo, em $49,1 \%$ do total dos entes pesquisados foi criado um gabinete de gestão das relações trabalhistas, sendo que nas províncias esse percentual chegou a $85,7 \%$ e nas prefeituras, a $44 \%$.

Além do tipo de ente e da localização geográfica (levemente inferior nos entes do sul da Itália), a presença de um gabinete específico para a gestão das relações sindicais também se relacionou com o tamanho da administração: nas prefeituras com menos de 15 mil habitantes a propensão a ter um gabinete desse tipo foi de $27,8 \%$, enquanto nas prefeituras com mais de 15 mil habitantes foi de $63 \%$.

Todavia, mesmo com a criação dos gabinetes, a reforma teve baixo impacto nas relações trabalhistas. O número de acordos nas negociações sindicais permaneceu inalterado no período 2002-2012, assim como a frequência das reuniões entre sindicatos locais e representantes da administração pública.

De qualquer forma, foi nas províncias onde se observou uma maior atividade sindical. Especialmente nas prefeituras com mais de 15 mil habitantes, a propensão de os gestores realizarem reuniões com os sindicatos foi mais elevada. Na maioria dos casos (80\%), foram mais de seis encontros ao ano que trataram, principalmente, de assuntos ligados a questões salariais, ou seja, disponibilidade de recursos orçamentários: progressões horizontais, distribuição de salário de produtividade, outras formas de indenização, progressões verticais e horizontais. Já os itens menos debatidos foram: critérios de avaliação da carga de trabalho, capacitação e avaliação da produtividade.

Em síntese, no que se refere ao conteúdo das relações trabalhistas, ainda que as negociações tenham envolvido temas relacionados com a parcela variável dos salários a serem pagos mediante critérios de produtividade, pouco foram debatidas outras inovações em termos das formas e estratégias de reorganização laboral do ente, assim como a respeito da avaliação dos servidores.

$\mathrm{Na}$ prática inexistiram diferenças significativas entre os entes que criaram e os que não criaram organismos específicos para tratar das negociações trabalhistas. Os dados analisados indicam que a partir da reforma administrativa houve um clima de cooperação entre as partes, sendo que em $75 \%$ dos casos não existiu nenhum tipo de ruptura das negociações entre sindicatos e entes locais.

Da forma como foi desenvolvida a reforma, as relações trabalhistas foram privilegiadas no debate sobre a repartição da quota orçamentária de produtividade, deixando de lado outros aspectos centrais como, por exemplo, a organização ad hoc do trabalho dos servidores. Dessa maneira, mesmo a reforma oferecendo 
instrumentos para estabelecer uma nova política de recursos humanos, as tarefas e organização do trabalho continuaram inalteradas e reproduziram lógicas organizacionais tradicionais na administração pública italiana.

\section{O impacto da reforma administrativa nos entes locais}

A reforma italiana almejou introduzir novas práticas de organização do trabalho objetivando aumentar a flexibilidade organizativa da administração pública. No entanto, a aplicação das novas normas contratuais nem sempre favoreceu uma reorganização da máquina administrativa. Entre as práticas utilizadas pelos gestores incluídos na amostragem (Tabela 1), aparecem com mais frequência a flexibilidade do horário de trabalho (71,8\%), a flexibilidade funcional $(55,7 \%)$ e a organização de trabalho por grupos $(53,4 \%)^{12}$.

Tabela 1 - Efetivação das práticas de organização do trabalho contidas na reforma

\begin{tabular}{ll}
\hline N=209 & $\begin{array}{l}\text { Valores percentuais: } \\
\text { "Sim, utiliza-se }[. . .] "\end{array}$ \\
\hline Fipo de prática existente no ente* & $71,8 \%$ \\
Mobilidade/flexibilidade funcional & $55,7 \%$ \\
Grupos de trabalho & $53,4 \%$ \\
Outras formas de envolvimento direto dos servidores & $30,7 \%$ \\
Definição de novos perfis organizacionais & $19,3 \%$ \\
Rodízio das tarefas & $19,1 \%$ \\
Grupos de melhoria & $11,2 \%$ \\
Círculos de qualidade & $1,7 \%$ \\
\hline
\end{tabular}

Fonte: Elaboração própria.

\footnotetext{
${ }^{12}$ Visando desenvolver uma avaliação mais ampla da reforma, em 2008 foi realizado um survey coordenado pelo ARAN centrado na gestão dos recursos humanos e das relações de trabalho no âmbito da administração pública italiana; mais especificamente, a amostra da pesquisa inclui um total de 209 entes locais: 187 municípios e 22 províncias, sendo definida a amostragem com base numa estratificação por tipo de instituição (comunas ou províncias), posição geográfica (as macrorregiões do Norte, Centro e Sul da Itália), e o número de habitantes geridos pelos entes públicos. Os questionários foram entregues aos responsáveis dos recursos humanos de cada administração, ao longo dos meses de setembro e outubro de 2008. Dos municípios estudados, 38,5\% não têm mais do que 10 mil habitantes, 35,3\% possuem entre 10.001 e 50 mil habitantes e $26,2 \%$ possuem mais de 50 mil habitantes. Do ponto de vista da distribuição geográfica, predominaram as administrações localizadas nas regiões Sul e Norte: $42,8 \%$ dos municípios pertencem à macrorregião Norte da Itália, 17,1\% pertence ao Centro e, finalmente, $40,1 \%$ ao Sul e ilhas.
} 
Visando ampliar a análise da efetividade da reforma administrativa italiana em nível local, propomo-nos a utilizar um índice de inovação da gestão organizacional, formado pela soma das oito variáveis dicotômicas presentes na Tabela 1: um índice aditivo cuja pontuação máxima seria "8" (no caso em que todas as práticas sejam atendidas) e mínima " 0 " (no caso de nenhuma prática ser atendida) ${ }^{13}$.

De acordo com a Tabela 1, somente uma minoria dos entes pesquisados aplicou todas ou a maioria das práticas permitidas pela reforma. Entre as medidas mais adotadas, houve uma preferência disparada pela flexibilidade do horário de trabalho e a mobilidade funcional, aspectos diretamente relacionados com a organização das rotinas de trabalho do funcionalismo. Numa margem oposta, a política menos implementada foi a dos círculos de qualidade, isto é, a organização espontânea de reuniões entre os trabalhadores com a finalidade de aprimorar a qualidade dos resultados do processo de trabalho.

Por meio das informações da tabela subsequente, é perceptível que a aplicabilidade da proposta foi maior entre os entes do norte do país $(3,12)$ e menor tanto entre os do sul $(2,55)$ quanto do centro (2,31). Igualmente se observam diferenças significativas no plano estatístico em relação ao número de habitantes por comuna. Nesse caso, entre as comunas com menos de 15 mil habitantes, o índice é igual a 1,73; já nas comunas maiores é de 3,71. O tipo de ente público também reflete um valor diferente do índice: entre as comunas o índice é de 2,64, portanto, inferior ao das províncias $(3,85)$.

As conclusões, em termos da aplicação dos procedimentos de inovação presentes na reforma italiana, definidas a partir das dimensões apresentadas na Tabela 2, podem ser resumidas da seguinte maneira: a) a gestão é mais inovadora no norte da Itália do que em outras regiões; b) as províncias são mais inovadoras do que as comunas e, finalmente; c) a inovação é maior entre as comunas e províncias com maior número de habitantes.

\footnotetext{
${ }^{13}$ Sendo assim, o nível global de inovação - o índice aditivo assim definido - pode ser associado às principais características do ente (tipo de instituição, número de habitantes ou localização geográfica, por exemplo); o Teste de Fisher destaca geralmente diferenças significativas entre as médias calculadas nos grupos.
} 
Tabela 2 - Inovação gerencial; divisão regional, tipo e tamanho do ente ( $\min .0$; máx. 8)

\begin{tabular}{|c|c|c|c|c|}
\hline & & $\mathrm{N}$ & Valor médio & Sig. \\
\hline \multirow{3}{*}{ Divisão regional } & Norte & 50 & 3,12 & \multirow{3}{*}{$\mathrm{p}<0,05$} \\
\hline & Centro & 19 & 2,55 & \\
\hline & Sul e Ilhas & 27 & 2,31 & \\
\hline \multirow{2}{*}{ Tipo de ente } & Comunas & 98 & 2,64 & \multirow{2}{*}{$p<0,05$} \\
\hline & Províncias & 14 & 3,85 & \\
\hline \multirow[t]{2}{*}{ Tamanho do ente } & Inferior a 15000 hab. & 53 & 1,73 & \multirow{2}{*}{$p<0,05$} \\
\hline & Superior a 15000 hab. & 45 & 3,71 & \\
\hline
\end{tabular}

Fonte: Elaboração própria.

Outro intuito da reforma foi a tentativa de favorecer a capacitação dos servidores: conforme os dados, essa proposta foi levada adiante por $83,1 \%$ das administrações incluídas na amostra. Entre as modalidades de formação efetivadas, há predominância da capacitação para execução de procedimentos administrativos específicos $(86,9 \%)$, formação técnica visando atender a tarefas atribuídas aos empregados (86\%), e relacionadas com meio ambiente e segurança no trabalho $(80,8 \%)$.

De maneira semelhante ao que ocorreu anteriormente, no caso do índice de inovação gerencial formado a partir de variáveis dicotômicas, também foi possível construir um índice aditivo da atividade de capacitação promovida pelo ente e logo especular uma correlação entre os índices.

Nesse aspecto, as conclusões vão ao encontro daquilo que foi observado em relação à inovação gerencial (Tabela 3): a) entre os entes do Norte, observa-se uma pontuação média maior; b) entre as províncias, o índice é maior do que nas comunas; e c) nas comunas e províncias com mais de 15 mil habitantes, o índice é maior em relação aos municípios menores $(4,7)$. 
Tabela 3 - Estatísticas descritivas do índice relativo à atividade de formação, repartição territorial, tipo de ente, tamanho do ente (min. 0; máx. 11)

\begin{tabular}{|c|c|c|c|c|}
\hline & & $\mathrm{N}$ & Valor médio & Sig. \\
\hline \multirow{3}{*}{ Divisão Regional } & Norte & 50 & 7,24 & \multirow{3}{*}{$p<0,05$} \\
\hline & Centro & 19 & 6,94 & \\
\hline & Sul e Ilhas & 27 & 5,48 & \\
\hline \multirow{2}{*}{ Tipo de ente } & Comunas & 82 & 6,24 & \multirow{2}{*}{$p<0,05$} \\
\hline & Províncias & 14 & 9,28 & \\
\hline \multirow[t]{2}{*}{ Tamanho do ente } & Inferior a 15000 hab. & 36 & 4,77 & \multirow{2}{*}{$p<0,05$} \\
\hline & Superior a 15000 hab. & 46 & 7,39 & \\
\hline
\end{tabular}

Fonte: Elaboração própria.

Observa-se que existe uma quota de variação em comum entre o índice de formação e o índice anterior de inovação gerencial: nesse caso, o coeficiente de correlação bivariada de Pearson retorna a um valor positivo de $r=0,58$ : a uma maior formação corresponde uma maior inovação organizativa.

Ferramentas de comunicação interna representam outro dos elementos que podem ser considerados centrais no processo de inovação organizacional. Esse mecanismo tem diversas finalidades como a previsão de situações de tensão e conflito organizacional, auxílio na compreensão das políticas e dos programas governamentais especialmente no contexto de mudanças organizacionais, estímulo ao sentimento de pertencimento por parte dos funcionários (commitment), orientação de cada servidor sobre atividades administrativas. Como decorrência disso, o uso estratégico da comunicação interna contribui para a criação de valores compartilhados, agiliza o intercâmbio de informações visando melhorias nas atividades decorrentes da função pública (BROTTO, 2006). 
Tabela 4 - Uso de ferramentas de comunicação interna (valores percentuais)*

\begin{tabular}{lccccc}
\hline & $\mathrm{N}$ & Sim & Ocasionalmente & Não & Total \\
\hline $\begin{array}{l}\text { 1. Newsletter ou } \\
\text { Boletins internos }\end{array}$ & 114 & $19,3 \%$ & $24,6 \%$ & $56,1 \%$ & $100 \%$ \\
\hline $\begin{array}{l}\text { 2. Encontros com os } \\
\text { funcionários sobre } \\
\text { programas ou objetivos } \\
\text { do ente }\end{array}$ & 115 & $13 \%$ & $46,1 \%$ & $40,9 \%$ & $100 \%$ \\
\hline \begin{tabular}{l} 
3. Pesquisa de opinião \\
\hline
\end{tabular} & 113 & $3,5 \%$ & $26,5 \%$ & $69,9 \%$ & $100 \%$ \\
\hline
\end{tabular}

Fonte: Elaboração própria.

As conclusões que derivam desses itens oferecem uma imagem crítica do uso dessas ferramentas (Tabela 4). Somente um em cada quatro entes locais realiza esporadicamente pesquisas de opinião; $56 \%$ não costumam utilizar newsletters ou boletins internos e em apenas 3,5\% dos casos as chefias dos entes organizam reuniões periódicas com os funcionários visando debater programas ou objetivos da administração pública. Por decorrência, a comunicação organizacional esteve entre os aspectos com menor aplicação do conjunto das medidas propugnadas pela reforma italiana.

A análise das três variáveis expostas até o momento (gestão inovadora, políticas de capacitação e uso da comunicação interna) retorna em geral valores significativos e positivos de correlação ${ }^{14}$. Em outros termos, podemos ser categóricos ao afirmar que, quando realizadas as melhorias na gestão, essas são geralmente acompanhadas por um uso estratégico das políticas de capacitação e da comunicação interna (Tabela 5).

${ }^{14}$ Ver os valores de $r$ de Pearsons na Tabela 5. 
Tabela 5 - Inovação, formação e comunicação (correlações momento zero e correlações parciais)

\begin{tabular}{llll}
\hline & Inovação & Formação & Comunicação \\
\hline Inovação & 1 & $0,59^{* *}$ & $0,50^{* *}$ \\
Correlações parciais & & $0,49^{* *}$ & $0,33^{* *}$ \\
$\mathrm{~N}$ & 112 & 89 & 108 \\
\hline Formação & 1 & $0,31^{* *}$ \\
Correlações parciais & & 0,12 \\
$\mathrm{~N}$ & 96 & 93 \\
\hline Comunicação (P. 34) & & 1 \\
$\mathrm{~N}$ & & 114 \\
\hline$* *$ Correlação é significativa ao nível de 0,01 (2-tailed) & \\
\hline Fonte: Elaboração própria. & &
\end{tabular}

Resumidamente, a inovação organizativa, quando introduzida na gestão do ente, tem um efeito cumulativo e sistêmico: a inovação gera inovação. Isso tende a destacar uma melhoria dessas práticas, favorecidas por um uso mais flexível dos recursos humanos (conforme o intuito da reforma). Mas, quando se trata da Itália contemporânea, um dos temas que mais acapara atenções é a questão meridional, alçada pelo teórico Antonio Gramsci à condição de núcleo explicativo sobre as diferenças regionais no país.

$\mathrm{Na}$ teoria do capital social, por exemplo, existiria uma linha divisória que diferenciaria as administrações locais no norte e no sul do país, afetando questões como a difusão da confiança interpessoal, as normas que governam a coexistência entre diferentes setores sociais, a formação de redes de associacionismo cívico etc. Seria precisamente por causa de uma menor dotação de capital social que as prefeituras do sul da Itália seriam menos eficientes que as do norte (PUTNAM, 1993; CARTOCCI, 2007). Nas regiões do sul, as práticas de familismo amoral (BANFIELD, 1958) favoreceriam uma cultura política baseada em princípios particularistas em detrimento da eficiência administrativa e do universalismo da civicness predominante no norte do país (ZINN, 2001).

Ainda que existam diferenças entre as prefeituras do sul e do norte da Itália, pelo que se refere à introdução de práticas inovadoras, nossa análise aponta que os principais problemas são semelhantes nas administrações de todo o país, independentemente da localização regional. Um exemplo disso é o caso dos prêmios de produtividade dos servidores.

Em quase $90 \%$ das prefeituras incluídas na amostragem foram fixados os objetivos anuais e oferecidos prêmios salariais por produtividade; com isso, em 
quase a metade dos entes locais pesquisados - sem diferenças entre norte e sul do país - os objetivos da administração não foram prefixados com antecedência (por exemplo, no início do ano de exercício), impedindo um efetivo planejamento da administração, assim como uma efetiva avaliação dos servidores e a redistribuição correspondente dos prêmios de produtividade. Por isso que, somente em poucos casos, houve uma distribuição diferenciada dos prêmios de produtividade.

\section{Considerações finais}

Se a corrupção política é considerada um fenômeno social, não apenas um problema oriundo de desvios individuais, a ideia de que a punição dos culpados deve ser acompanhada por mudanças de fundo na estrutura política da sociedade ganha relevo. Essa foi a direção apontada pela estratégia italiana, articulando propostas de reformas das estruturas estatais com o julgamento e punição de envolvidos com o desvio de recursos públicos e o recebimento ilegal de propina. Contudo, mesmo tendo um sentido correto, a reforma administrativa italiana não funcionou de acordo com o previsto.

$\mathrm{Na}$ literatura especializada existem diferentes explicações sobre o fracasso dos planos de reforma administrativa (RESENDE, 2002). Muito frequentemente justificativas sobre o tema estão centradas ou em explicações de corte institucional, ou seja, características específicas das instituições públicas que dificultam as mudanças; ou em explicações de corte cultural, que se relacionam com as limitações dos atores envolvidos no processo. Ambos os fatores foram importantes no caso italiano, porém, soma-se aos mesmos um terceiro elemento central que diz respeito ao desenho da reforma, isto é, o modelo de mudança institucional proposto baseado na adaptação de uma dinâmica empresarial ao setor público.

Teoricamente, o modelo italiano de reforma administrativa dos anos 1990 pode ser enquadrado naquilo que Osborne e Gaebler (1992) chamaram de uma reinvenção do governo: uma administração pública centrada na prestação de serviços, organizada a partir de uma planificação de metas e busca de resultados, com um corpo de funcionários públicos assentado num regime flexível de trabalho incentivado por um plano de recompensas de acordo com a produtividade.

Contudo, na prática, serve de exemplo de que nem todo o modelo administrativo aplicado na esfera privada funciona bem quando se trata de administração pública.

Como já destacado, a reforma pretendeu favorecer uma maior divisão de funções entre a parte política e gerencial da administração pública. Porém, a quase totalidade dos gerentes entrevistados respondeu que o planejamento administrativo sempre era negociado entre políticos e gerentes administrativos, o que indica que a divisão 
organizativa entre funções políticas e administrativas não funcionava; logo, um dos eixos da reforma não foi alcançado.

Em termos do funcionalismo público, a proposta de mudança administrativa partiu do pressuposto da necessidade de criar mecanismos que estimulassem a livre-competição entre os trabalhadores, premiando aqueles que atingissem melhor desempenho. Não obstante, como observado, as metas foram definidas ao longo do ano de exercício e não no início, o que indica uma ausência do planejamento do ente. Além disso, chama a atenção o fato de que, na quase totalidade dos entes, todos os servidores atingiram suas metas de trabalho e, portanto, mereceram o adicional de produtividade máximo de salário: ganharam prêmios de produtividade por terem alcançado metas anuais estabelecidas no segundo semestre do ano de exercício.

Aliás, na metade dos entes locais a quota orçamentária destinada ao pagamento dos prêmios de produtividade foi utilizada integralmente; na outra metade, foi consumida entre $90 \%$ e $99 \%$ do montante disponibilizado no orçamento. Isso fortalece a conclusão de que a introdução de práticas inovadoras foi parcial, sobretudo no sul do país.

Nas últimas décadas a política italiana foi atingida por diversos escândalos que minaram a confiança dos eleitores em relação aos gestores públicos e intervenção do Estado. A tentativa de reforma administrativa - além da redução das transferências aos entes locais, os cortes orçamentários e o aumento da dívida do Estado e dos entes locais que favoreceu a privatização de vários serviços - foi, em grande parte, reflexo dessa situação. Como os entes públicos e a gestão governamental dos dirigentes eleitos funcionavam com precariedade, a opção foi redirecionar o gerenciamento público para os modelos advindos da iniciativa privada.

Porém, o emprego de estratégias vinculadas ao funcionamento de estruturas relacionadas com o mercado econômico numa organização dirigida para o desenvolvimento de políticas públicas não é tarefa fácil. A administração das empresas privadas é constituída pela defesa de interesses particulares dos seus proprietários, é submetida a uma dinâmica que visa à acumulação de capital. Já a administração pública não está - ou não deveria estar - direcionada para a acumulação privada de rendimentos para seus dirigentes, pois tem como finalidade a administração de bens coletivos, a prestação de serviços e o atendimento de demandas sociais.

Sobrepondo uma lógica a outra, o resultado, no caso italiano, acabou sendo a criação de um sistema desfigurado que não conseguiu atender a nem uma perspectiva, nem outra, ampliando ainda mais o desconforto dos cidadãos em relação à classe política e aos dirigentes governamentais. 


\section{Referências bibliográficas}

ABRUCIO, F. L. Trajetória recente da gestão pública brasileira: um balanço crítico e a renovação da agenda de reformas. Revista Brasileira de Administração Pública, v. 1, p. 77-87, 2007.

Amato, Ciro; Braga, Adolfo; Carrieri, Domenico; Cordella, Caterina; Tome, Roberto. Il lavoro atipico nelle pubbliche amministrazioni locali. Un contributo scientifico della scuola superiore della pubblica amministrazione locale. Roma: SSPAL, 2009.

BANFIELD, Edward. The moral basis of a backward society. New York: The Free Press, 1958.

BACCARO, Lucio. Contrattazione politica e consultazione dei lavoratori. Quaderni di Rassegna sindacale, v. 9, n. 1, p. 125-135, 2008.

BARBIERI, P.; SCHERER, S. Le conseguenze sociali della flessibilizzazione del mercato del lavoro in Italia. Stato e Mercato, v. 74, n. 2, p. 291-321, 2005.

Bоввіо, Norberto. Entre duas Repúblicas. Brasília: UnB, 2001.

BRotTo, Carla. Innovare con la comunicazione interna. Comuni d'Italia, n. 3, MAggioli Editore: Rimini, 2006.

BordognA, Lorenzo. Le relazioni sindacali nel settore pubblico. In: CELLA, G. P. ;

TREU, T., (orgs.). Le nuove relazioni industriali: l'esperienza italiana nella prospettiva europea. Bolonha: il Mulino, 1998.

Contrattazione integrativa e gestione del personale nelle pubbliche amministrazioni: un'indagine sull'esperienza del quadriennio 1998-2001. Milão: Franco Angeli, 2003.

CARRIERI, Mimmo; RICCIARDI, Mario. L'innovazione imperfetta. Casi di contrattazione integrativa negli enti locali. Bolonha: il Mulino, 2006.

CARTOCCI, Roberto. Mappe del tesoro. Atlante del capitale sociale in Italia. Bolonha: il Mulino, 2007.

CRISTOFOLI, Daniela; TURRINI, Alex; VAlOTTI, Giovanni. Da burocrati a manager: una riforma a metà. Primo rapporto sulla dirigenza pubblica italiana. Milão: Egea, 2007. D’ALOIA, Giuseppe. La difficoltà di valutare ed essere valutati. Innovazione legislativa, contrattuale ed organizzativa negli Enti Locali: quattro case studies nel Mezzogiorno d'Italia. In: CARRIERI, M.; RICCIARDI, M. (orgs.). L'innovazione imperfetta. Casi di contrattazione integrativa negli enti locali. Bolonha: il Mulino, 2006.

Della RoccA, Giuseppe. Misurazione e governance. Aran Newsletter, 1-2 (14), p. 10-13, 2009.

ECHABARRIA, Koldo; Cortazar, Juan Carlos. Public Administration and Public Employment Reform in Latin America. In: LoRA, Eduardo (ed). The state of state reform in Latin America. Washington: The Inter-American Development Bank, 2007. GENTILE, Michele. Le stagioni del lavoro pubblico. Quaderni di Rassegna Sindacale, v. 51, n. 3, p. 85-98, 2012. 
LIMA JR., Olavo Brasil de Lima. As reformas administrativas no Brasil: modelos, sucessos e fracassos. Revista do Serviço Público, ano 49, v. 49, n. 2, p. 2-33, 1998. LoNGo, Francisco. Mérito e flexibilidade: a gestão de pessoas no setor público. São Paulo: Fundap, 2007.

Moron, Miguel Sanchez. Sobre la reforma administrativa en Itália del período de transición. Revista de Administración Pública, n. 134, p. 71-489, 1994.

ONGARO, Edoardo. Public management reform and modernization: trajectories of administrative change in Italy, France, Greece, Portugal and Spain. Glos: Edward Elgar Publishing, 2009.

OSBORNE, David; GAEBLER, Ted. Reinventing government: how the entrepreneurial spirit is transforming the public sector. Reading: Addison-Wesley, 1992.

PEREIRA, Luiz Carlos; SPINK, Peter. Reforma do Estado e administração pública gerencial. Rio de Janeiro: Editora FGV, 2005.

A reforma do Estado nos anos 90: lógica e mecanismos de controle.

Lua Nova, n. 45, p. 49-95, 1998.

PollitT, C; BouckAeRT, G. Avaliando reformas da gestão pública: uma perspectiva internacional. Revista do Serviço Público, Brasília, v. 53, n. 3, p. 5-29, jul./set. 2002.

PUTNAM, Robert David. La tradizione civica nelle regioni italiane. Milão: Arnoldo Mondadori Editore, 1993.

Resende, Flavio da Cunha. Por que reformas administrativas falham? Revista Brasileira de Ciências Sociais, v. 17, n. 50, p. 123-184, out. 2002.

RICCI, Paolo. Em que ponto estamos? Sessenta anos de reformas institucionais na Itália (1946-2005). DADOS, v. 49, n. 4, p. 751-793, 2006.

RICCIARDI, Mario. Tra passato e presente: un tentativo di lettura. Quaderni di Rassegna Sindacale, v. 51, n. 3, p. 63-84, 2012.

SANO, Hinorobu; ABRUCIO, Fernando. Promessas e resultados na nova gestão pública no Brasil. RAE, v. 48, n. 3, p. 64-80, 2008.

SISMONDI, Carlo Mochi. I dipendenti pubblici in Italia. Roma: Forum Pa Edizioni, 2013.

Rızzo, Sergio; Stella, Gian Antonio. La casta. Milão: Rizzoli, 2007.

SOUSA, Celina; CARVALHo, Inaiá. Reforma do Estado, descentralização e desigualdades. Lua Nova, n. 48, p. 187-212, dez. 1999.

ZINN, Dorothy. La raccomandazione. Clientelismo vecchio e nuovo. Roma: Donzelli, 2001. 


\section{Davide Carbonai}

Doutor em Sociologia Econômica (Università di Teramo, Itália). Professor no Programa de Pós-Graduação em Administração, no Programa de Pós-Graduação em Ciência Política da Universidade Federal do Rio Grande do Sul (UFRGS) e no Departamento de Ciências Administrativas da UFRGS. Contato: davide.carbonai@ufrg.br

\section{Alfredo Alejandro Gugliano}

Doutor em Ciências Políticas e Sociologia (Universidad Complutense de Madrid, Espanha), Professor do Departamento de Ciência Política da Universidade Federal do rio Grande do Sul (UFRGS) e Pesquisador do CNPq. Contato: alfredogugliano@hotmail.com 